\title{
Pulmonary aspergilloma, an unusual complication in Wegener's granulomatosis
}

\author{
J. MARTENS \\ M.D. \\ Department of Pulmonary Diseases and Internal Medicine, Academische Ziekenhuizen, \\ Katholieke Universiteit Leuven B-3000 Belgium
}

\begin{abstract}
Summary
A patient with a limited form of Wegener's granulomatosis is presented. The disease was complicated by the development of an aspergilloma in the excavated pulmonary infiltrate.

\section{Introduction}

With the increase in survival as a result of cyclophosphamide therapy, new complications of Wegener's granulomatosis have been encountered. These include the adverse effects of treatment,
\end{abstract}

bacterial infections of the nose and paranasal sinuses (Fauci and Wolff, 1973), obstructive laryngitis (personal observation) and subacute or chronic endobronchial disease which may lead to progressive narrowing and stenosis (Flye, Mundinger and Fauci, 1979). Another, albeit not totally unexpected, type of complication is now described.

\section{Case history}

A 50-year-old woman was diagnosed as having a limited form of Wegener's granulomatosis in April

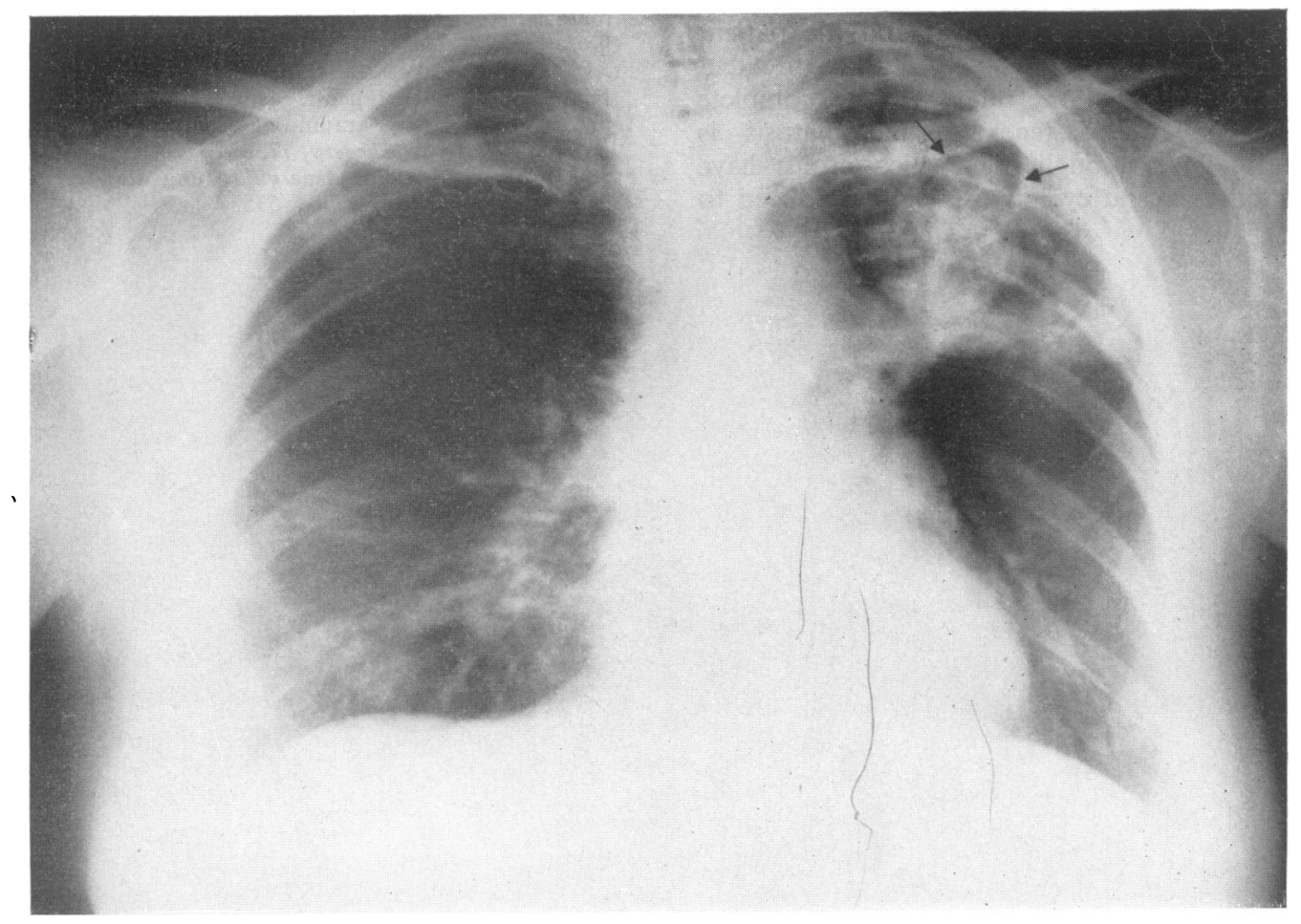

FIG. 1. Chest film of a case of Wegener's granulomatosis. A fungus ball surrounded by a semicircular air shadow (arrows) is seen in the excavated pulmonary infiltrate. 
1978. She presented with chest pain, cough, haemoptysis, hearing loss, fever and a poor general condition. A chest film disclosed a great cavitary infiltrate in the left upper lobe. Additional findings were a bilateral serous otitis media, clouding of the paranasal sinuses and an abdominal skin ulceration. The ESR was $130 \mathrm{~mm}$ in $1 \mathrm{hr}$. The urine was normal, as were other laboratory data.

The patient also experienced epistaxis. A biopsy of the skin lesion revealed fibrinoid necrotizing material surrounded by multinucleated giant cells, histiocytes and lymphoplasmocytes. A transthoracic needle aspiration of the left upper lobe was performed and examination of the tissue specimen showed a necrotizing inflammatory process with vasculitis. Infectious and malignant pathologies were excluded. Corticosteroids and azathioprine $150 \mathrm{mg} /$ day initially induced a remission. A minor relapse 7 months after presentation was easily controlled with cyclophosphamide, $125 \mathrm{mg} /$ day, and prednisone, $40 \mathrm{mg} /$ day. At that time, however, radiography disclosed a rounded mass in the excavated lung infiltrate, surrounded by a semicircular air shadow, apparently representing a mycetoma (Fig. 1). Since then, several sputum cultures have yielded Aspergillus, and serum precipitins, which were formerly negative for this pathogen, have become positive, and the patient has experienced recurrent, though not life-threatening, haemoptysis. On the other hand, a complete remission of the Wegener's granulomatosis is maintained, even though the corticosteroids have been withdrawn and cyclophosphamide reduced to
$50 \mathrm{mg} /$ day. However, only partial resolution of the pulmonary infiltrate has been achieved, apparently because of the presence of the aspergilloma.

\section{Discussion}

Pulmonary aspergillomas have been identifiec in association with a wide variety of lung diseases $\overline{\bar{c}}$. including tuberculosis, sarcoidosis, asbestosis, histoळ plasmosis, ankylosing spondylitis, bronchiectasis bronchial cysts and malignancy. The presence of $\alpha^{\infty}$ pre-existing lung cavity appears to be the mosp common predisposing factor to the formation of an aspergilloma (Pennington, 1980). In Wegener' granulomatosis, excavation of the lung infiltratess occurs in roughly $50 \%$ of cases (Fauci and Wolff 1973). Unless complete resolution is achieved vegetation of Aspergillus in these cavities mayo occur, as illustrated in this case. The development of an aspergilloma, causing haemoptysis and changing the radiological appearance of the lungr infiltrate, should not be confused with disease activity of Wegener's granulomatosis.

\section{References}

FAUCI, A.S. \& WolfF, S.M. (1973) Wegener's granulomatosis: studies in eighteen patients and a review of hos literature. Medicine, 52, 535.

Flye, M.W., Mundinger Jr, G.H. \& FAuCi, A.S. (1970 Diagnostic and therapeutic aspects of the surgical apo proach to Wegener's granulomatosis. Journal of Thoracics and Cardiovascular Surgery, 77, 331.

Pennington, J.E. (1980) Aspergillus lung disease. Medica Clinics of North America, 64, 535. 